ORIGINAL ARTICLE

\title{
Antimicrobial and plant growth-promoting properties of the cacao endophyte Bacillus subtilis ALB629
}

\author{
L.L. Falcäo ${ }^{1}$, J.O. Silva-Werneck ${ }^{1}$, B.R. Vilarinho ${ }^{2}$, J.P. da Silva ${ }^{1}$, A.W.V. Pomella ${ }^{3}$ and L.H. Marcellino ${ }^{1}$ \\ 1 Embrapa Genetic Resources and Biotechnology, Brasília, DF Brazil \\ 2 Department of Brasilia, Department of Forest Engineering, Brasília, DF Brazil \\ 3 Sementes Farroupilha, Laboratory of Biocontrol, Patos de Minas, MG Brazil
}

\section{Keywords}

antimicrobials, Bacillus, biocontrol, fungi, plant pathology.

\section{Correspondence}

Lucilia H. Marcellino, Embrapa Genetic Resources and Biotechnology - PqEB - Av. W5 Norte (final), 70770-917, Brasília, DF, Brazil.

E-mail: lucilia.marcellino@embrapa.br

2013/2256: received 11 November 2013, revised 30 January 2014 and accepted 17 February 2014

doi:10.1111/jam.12485

\begin{abstract}
Aims: To investigate the effects of the endophyte Bacillus subtilis ALB629 on the growth of cacao seedlings at early developmental stage and to evaluate its antimicrobial properties.

Methods and Results: Germinating cacao seeds were inoculated with ALB629, and seedlings growth was evaluated 30 days later. Significant increase $(P<0.05)$ was observed in the root system (up to $30 \%$ ), leaf area (14\%) and stem height (7.6\%). ALB629 colonized the entire plant, prevailing over indigenous micro-organisms. In addition, it was tested in vitro, by pairing assays, and showed antagonistic effect against the phytopathogenic fungi Moniliophthora perniciosa, Colletotrichum sp. and C. gossypii. When tested in cacao-grafting procedure in the field, ALB629 increased the grafting success rate (24\%), indicating its protective effect. In addition, this Bacillus secretes an antagonist compound, as shown by the antifungal activity of the cell-free culture.

Conclusions: Bacillus subtilis ALB629 promotes cacao root growth, besides promoting growth of the aerial part of cacao seedlings. It has antimicrobial properties and produces an antifungal compound.

Significance and Impact of the Study: ALB629 presented beneficial characteristics for cacao cultivation, being a good biological control agent candidate. Furthermore, it is a potential source of antifungal compound with potential for commercial exploitation.
\end{abstract}

\section{Introduction}

The cultivation of cacao (Theobroma cacao L.) has great economic importance worldwide. Cocoa annual production is around 4.3 million tons (2010/2011 season), with increasing demand. The production is restricted to some countries, being Ivory Coast (Côte d'Ivoire) and Ghana the world's two largest producers, accounting for nearly $60 \%$ of the world production (ICCO 2010). This context makes the cocoa supply more vulnerable to political and economic instabilities of a few countries. Cacao is also susceptible to various abiotic and biotic stresses, such as those caused by diseases. Indeed, cacao plants are affected by several diseases, such as witches' broom, frosty-pod rot and black-pod rot caused by the fungi Moniliophthora perniciosa, M. roreri and Phytophthora spp., respectively, that generate heavy production losses (Bowers et al. 2001). Several strategies, including chemical control, phytosanitary pruning and use of resistant cultivars, are used in integrated disease management programmes. These strategies are not always sufficient, and the use of agrochemicals, such as copper-based fungicides and systemic fungicides, can be harmful to the environment and to the workers' health. Furthermore, considering that cacao is mainly grown by smallholder farmers, the application of commercial fungicides is often limited (Acebo-Guerrero et al. 2012). Thus, sustainable strategies to be included in integrated pest management of cacao are sought. The use of antagonistic micro-organisms naturally found in the phyllosphere and rhizosphere, including the endophytes, is among these strategies. 
Some endophytic fungi and bacteria associated with cacao have been investigated. The diversity of the endophytic community was studied, and it was found that Gliocladium catenulatum reduces the incidence of witches' broom in cacao seedlings by $70 \%$ (Rubini et al. 2005). Bae and co-workers have shown that the isolate DIS219b of Trichoderma hamatum was able to promote T. cacao plant growth and to cause a delay in many aspects of the plant drought response (Bae et al. 2009). The endophyte Trichoderma martiale strain ALF 247 was demonstrated to reduce black-pod rot disease, caused by Phytophthora palmivora, when sprayed on cacao pods in the field (Hanada et al. 2009). In another study, Trichoderma spp. isolated from cacao have been shown to be endophytic and to produce a volatile/diffusible antibiotic that inhibits the development of the cacao's pathogenic fungus M. roreri (Samuels et al. 2006). A study with Bacillus spp. demonstrated that Bacillus cereus isolated from potato and tomato were able to become endophytic in cacao and that the isolate BT8, from tomato, caused significant reduction in black-pod rot (Phytophtora capsici) on cacao leaves (Melnick et al. 2008). More recently, it was suggested that endophytic endosporeforming bacteria isolated from $T$. cacao could serve as potential biological control agents of cacao diseases (Melnick et al. 2011).

Bacteria of the genus Bacillus are good candidates for using as biological control agents. They are able to produce a broad array of biologically active molecules, such as antimicrobial compounds, and their spore resistance to desiccation is suitable for formulation of stable products (Castillo et al. 2013; Melnick et al. 2013; Lyngwi and Joshi 2014). Among the antimicrobial compounds, the lipopeptides can inhibit phytopathogen growth, facilitate root colonization and reinforce host resistance (Ongena and Jacques 2008). Moreover, in contrast to the chemical pesticides, they have low toxicity, high biodegradability and present environmentally friendly characteristics (Chen et al. 2008).

Recently, an isolate of Bacillus subtilis (ALB629) has been obtained from cacao plants in Brazil. It has been shown that it is a systemic colonizer and plant growth promoter, increasing the number of leaves and plant stem height, observed in 3-month-old plants (Leite et al. 2013). To further study its influence on plant growth, we have analysed the effect of ALB629 in the root system, as well as on the leaf area and stem height, earlier on plant development, in 4-week-old seedlings. In addition, to investigate the isolate's biocontrol potential, we have studied its antimicrobial activity in vitro against some phytopathogenic fungi and its relation to a secreted compound. We have also tested its overall beneficial activities in the field, based on cacao-grafting experiments.

\section{Material and methods}

\section{Bacillus subtilis ALB629}

Bacillus subtilis isolate ALB629 was obtained from healthy cacao trees according to the methodology of Rubini et al. (2005). It was maintained at $-80^{\circ} \mathrm{C}$ in liquid $\mathrm{LB}$ with $15 \%$ glycerol final concentration, at Embrapa Genetic Resources and Biotechnology. It has been elsewhere named B. subtilis 629 (Leite et al. 2013) and deposited into the Biological Institute Culture Collection of Phytopathogenic Bacteria - IBSBF (Campinas - SP, Brazil), under reference number IBSBF-3106.

\section{Plant material}

For plant inoculation with B. subtilis ALB629, cacao pods were collected from trees in the central and northern region of Brazil (Brasília - DF and Belém - PA, respectively). For the grafting procedure, the cacao clone CCN 51 and a common variety were used (Yamada et al. 2001).

\section{Seed preparation}

Cacao pods were washed with soap and tap water. The pods were opened and the seed's coats were removed under sterile conditions (laminar flow). The seeds were immediately immersed in sterile distilled water and then sterilized by successive washings: $70 \%$ ethanol for $2 \mathrm{~min}$, sterile distilled water for $2 \mathrm{~min}, 2 \cdot 5 \%$ sodium hypochlorite for $15 \mathrm{~min}$ and then rinsed three times with sterile distilled water. After the washings, the material was immersed in $1 \mathrm{mg} \mathrm{ml}{ }^{-1}$ ampicillin solution for $30 \mathrm{~min}$. Following sterilization, the seeds were allowed to germinate on $1 \%$ water agar medium for 5 days at room temperature, generating seedlings of approx. 2-cm-long radicles.

\section{Plant inoculation with Bacillus}

Bacillus subtilis isolate ALB629 was grown on LB agar plates for $48 \mathrm{~h}$, at $28^{\circ} \mathrm{C}$. The cells were scraped off and suspended in $100 \mathrm{ml}$ of $\mathrm{dH}_{2} \mathrm{O}$ (approx. $2 \times 10^{7}$ $\mathrm{CFU} \mathrm{m} \mathrm{m}^{-1}$ ). Half of the seedlings, prepared as described above, were used for inoculation and half for noninoculated control plants. The inoculation was performed by immersing cacao seedlings in bacteria suspension (or sterile distilled water for the control) for $10 \mathrm{~min}$, under sterile conditions of laminar flow without agitation. The experimental design consisted of two treatments, inoculated and non-inoculated (control). The experiment was repeated four times (replicates). The number of plants (n) per treatment in each replicate was 10, 12, 20 and 20. 
For fresh weight determination, one experiment consisting of 70 plants per treatment was performed.

\section{Cultivation of Theobroma cacao seedlings}

The inoculated and control seedlings were transferred to $300-\mathrm{ml}$ pots containing substrate for plants (Plantmax, Eucatex ${ }^{\circledR}$, Paulínia, SP, Brazil) mixed with red latosol soil (3:1), which had been autoclaved twice at $121^{\circ} \mathrm{C}$, $1 \mathrm{kgf} \mathrm{cm}{ }^{-2}$, for $1 \mathrm{~h}$. The seedlings were covered with a fine substrate layer, and the pots were kept covered with Parafilm ${ }^{\circledR}$ (Pechiney Plastic Packaging Inc, Chicago, IL) for 5 days. The plants were grown in the laboratory, at $25-28^{\circ} \mathrm{C}$, under natural daylight conditions and watered every other day with approx. $20 \mathrm{ml}$ of tap water.

\section{Plant growth evaluation}

The plant growth effects were evaluated in 30-day-old seedlings by the variables leaf area, plant height and morphometry/fresh weight of the root system.

The leaf area was assessed by measuring the length $(L)$ and maximum width $(W)$ of the first three leaves (bottom to top). The area was calculated using the area of an ellipse, $A=\pi / 4 \times W \times L$. This calculated area has a linear relationship to the leaf scanned area, as determined in our previous investigation, in which the areas of 50 leaves from cacao tree were measured by the Image Tool software, ver. 3.0 (http://compdent.uthscsa.edu/dig/down load.html) and compared to the calculated areas. A linear regression equation of $y=1.137 x-1.814$ with regression coefficient $R^{2}=0.989$ was obtained, where $y$ is the scanned area and $x$ is the calculated area.

Plant height was measured as the length of the stem, from apical meristem to the substrate surface. Root system was assessed by both morphometry and fresh weight. Root systems of 30-day-old plants were photographed using a Sony Cyber-shot digital camera. Digital images of the roots were analysed using Image J software package (http://rsb.info.nih.gov/ij). The integrated density (ID $=$ Area $\times$ total pixel $)$ was determined using binary image. It was used nine plants per treatment from two replicates. To assess fresh weight, 60-day-old seedlings were removed from the substrate, the hypocotyls and root system were detached and washed to remove any loose substrate. The material was gently blotted on paper towel and weighted immediately.

\section{Bacillus subtilis recovery}

For the recovery of B. subtilis ALB629, fragments of leaves, stems, roots and shoot apexes from 30-day-old inoculated seedlings were used. Non-inoculated plants were used as control. Micro-organisms on the surface of the samples were previously removed by successive washings with $70 \%$ ethanol for $1 \mathrm{~min}$, rinsed once with sterile distilled water, $2.5 \%$ sodium hypochlorite for $3 \mathrm{~min}$, $70 \%$ ethanol for $30 \mathrm{~s}$ and then rinsed three times with sterile distilled water. The tissues were then sectioned in $0.5-\mathrm{cm}$ to $1-\mathrm{cm}$ fragments, as follows: roots (primary and lateral), stem (epicotyl and hypocotyl), cotyledon, leaves (blade, petiole and veins) and shoot apex. The samples were distributed into LB agar plates and incubated for $2-3$ days at $28^{\circ} \mathrm{C}$. Extended incubation time (12 days) was used to analyse the influence of the ALB629 inoculation on micro-organisms that naturally occur in cacao. Colonization was observed by the growth of colonies with typical B. subtilis morphology on the evaluated tissue. Bacillus subtilis growth was confirmed by optical microscopy and genomic fingerprinting (BOX-PCR).

\section{BOX-PCR of bacterial isolates}

Some bacteria grown out of the explants of inoculated and non-inoculated seedlings in vitro were selected for repetitive sequence-based PCR (BOX-PCR) using the BOXA1R primer -5'CTACGGCAAGGCGACGCTGACG3' (Versalovic et al. 1994; Koeuth et al. 1995). A sample of each colony was streaked onto LB agar and incubated at $28^{\circ} \mathrm{C}$ for $24 \mathrm{~h}$. To obtain genomic DNA, individual colonies were transferred to $10 \mu \mathrm{l}$ of MilliQ water. After mixing, the cells were frozen at $-80^{\circ} \mathrm{C}$, overnight, then thawed and heated at $95^{\circ} \mathrm{C}$ for $5 \mathrm{~min}$. The suspensions were centrifuged at $10000 \mathrm{~g}$ for $1 \mathrm{~min}$. Supernatants containing genomic DNA were transferred to fresh 1.5$\mathrm{ml}$ tubes and stored at $-20^{\circ} \mathrm{C}$ until use.

PCR amplification was performed in modified Gitschier buffer $\left(16.6 \mathrm{mmol} \mathrm{l}^{-1}\left(\mathrm{NH}_{4}\right)_{2} \mathrm{SO}_{4}, 67 \mathrm{mmol} \mathrm{l}^{-1}\right.$ Tris- $\mathrm{HCl}$ pH $8.8, \quad 6.7 \mathrm{mmol} \mathrm{l}^{-1} \quad \mathrm{MgCl}_{2}, \quad 6.7 \mu \mathrm{mol} \mathrm{l}^{-1}$ EDTA, $30 \mathrm{mmol} \mathrm{l}^{-1}$ B-mercaptoethanol) (Kogan et al. 1987) plus $10 \%(\mathrm{v} / \mathrm{v})$ DMSO, $0 \cdot 16 \mathrm{mg} \mathrm{ml}^{-1} \mathrm{BSA}, 1.25 \mathrm{mmol} \mathrm{l}^{-1}$ each dNTP, $1.76 \mu \mathrm{mol} \mathrm{l}^{-1}$ BOXA1R primer, $2 \mathrm{U}$ Taq DNA polymerase (Phoneutria biotecnologia, Brazil), $1 \mu \mathrm{l}$ of template DNA in $50 \mu \mathrm{l}$ reaction, using the following program: one initial cycle at $95^{\circ} \mathrm{C}$ for $2 \mathrm{~min} ; 30$ cycles of $94^{\circ} \mathrm{C}$ for $3 \mathrm{~s}, 92^{\circ} \mathrm{C}$ for $30 \mathrm{~s}, 50^{\circ} \mathrm{C}$ for $1 \mathrm{~min}, 65^{\circ} \mathrm{C}$ for $8 \mathrm{~min}$; and a final extension at $65^{\circ} \mathrm{C}$ for $8 \mathrm{~min}$ in a thermal cycler PTC100 (MJ Research) according to Rademaker and de Bruijn (1997). Amplicons were resolved by electrophoresis in $1.8 \%$ agarose gel, in $0.5 \times$ TBE (Tris-borate-EDTA) buffer, containing $0 \cdot 5 \mu \mathrm{g} \mathrm{ml}^{-1}$ ethidium bromide.

\section{Antagonism to phytopathogenic fungi}

Bacillus subtilis ALB629 was cultivated on potato dextrose agar (PDA) plates, near to each of the following 
phytopathogenic fungus $M$. perniciosa, Fusarium solani $f$. sp. glycines, Colletotrichum sp. and C. gossypii. One colony of B. subtilis (taken with a toothpick) was inoculated in the centre of the plate, and four discs of mycelium (1-cm diameter) of each fungus were placed at equidistant points along the edge. The plates were incubated at $28^{\circ} \mathrm{C}$, with a photoperiod of $12 \mathrm{~h} / 12 \mathrm{~h}$, for 5 days. The influence of $B$. subtilis on the fungus growth was evaluated by the morphology of the mycelium and the presence of inhibition zone between the bacterium and the fungus.

\section{Antimicrobial compound investigation}

ALB629 was cultivated in LB medium at $28^{\circ} \mathrm{C}$, $200 \mathrm{rpm}$, for $24 \mathrm{~h}$. The culture was centrifuged at $5000 \mathrm{~g}$ for $20 \mathrm{~min}$. The supernatant was collected, filtered in $0 \cdot 22-\mu \mathrm{m}$ filter (Millipore) and added to PDA (20\% v/v). Mycelial discs (1-cm diameter) of C. gossypii and $M$. perniciosa were individually transferred to this medium and cultivated at $28^{\circ} \mathrm{C}$ for 5 days, in triplicates. The fungi growth was determined by measuring the mycelial diameters.

\section{Theobroma cacao grafting}

A commercial cacao plantation was used for grafting. Healthy branches of the clone CCN 51 were cut in $25-\mathrm{cm}$ pieces and then grafted onto cacao plants of the common variety. A batch of 50 grafts was sprayed with a bacterial suspension of $1-2 \times 10^{9} \mathrm{CFU} \mathrm{ml}^{-1}$ of ALB629, until near run-off. Fifty grafts were treated with the fungicide benomyl $\left(0.4 \mathrm{~g} \mathrm{l}^{-1}\right)$, and 50 grafts were sprayed with water, as positive and negative controls, respectively. Following the ordinary grafting procedure, a plastic bag was placed over each graft to function as a humidity chamber. The grafting success was evaluated 60 days later.

\section{Statistical analysis}

The leaf area and stem height means of inoculated and non-inoculated (control) plants were compared by mixed models, using the lmer library of the ' $\mathrm{R}$ ' statistical platform (R-Core-Team 2013), considering the replicates as a random effect.

For root system analyses, the integrated density (ID) means of inoculated and non-inoculated (control) plants were compared using the generalized linear model, assuming a Poisson distribution, as this variable assumes discrete values. In the case of the fresh weight analysis, it was assigned a gamma distribution due to the continuous and asymmetric distribution of the data. These analyses were developed using the $g l m$ library of the ' $\mathrm{R}$ ' package.
The grafting success rate between the treatments was also compared using generalized linear model, assigning a binomial distribution, as the variable analysed is a dichotomous variable.

For all statistical analyses, values of $P<0.05$ were considered significant.

\section{Results}

\section{Theobroma cacao growth promotion}

To evaluate the influence of the B. subtilis ALB629 on T. cacao growth, some parameters (leaf area, stem height and root system development) of the Bacillus-inoculated and non-inoculated seedlings were compared. The measures were determined in 30-day-old seedlings.

The data showed significant increase $(P<0.05)$ of about $14 \%$ in leaf area of the bacterium-inoculated plants $\left(64.37 \pm 21.94 \mathrm{~cm}^{2}\right)$ relative to the control $(56.42 \pm$ $\left.17 \cdot 18 \mathrm{~cm}^{2}\right)$. The analysis of the residual effects of the model showed that $66 \%$ of the variability refers to the differences between the batches and $34 \%$ to random causes. The variability due to the batch was filtered through mixed models, and, on average, the difference was evident.

The inoculated plants also showed significant increase $(P<0.05)$ in stem height of about $7.6 \%$ $(15.26 \pm 4.46 \mathrm{~cm})$ relative to the control $(14.18 \pm$ $4.27 \mathrm{~cm})$. The variability due to the batch was filtered through mixed models, and the analysis of the residual effects of the model revealed that most of the variability (92\%) refers to the differences between batches and the remainder $(8 \%)$ to random causes. An example of the difference in the plants stem height between treatments is shown in the Fig. 1a.

The root system of inoculated plants was significantly larger $(P<0.05)$ than the control. In one experiment, it was $30 \%$ larger (ID: $1.22 \times 10^{6}$ pixels $\pm 0.27 \times 10^{6}$ vs $0.94 \times 10^{6}$ pixels $\left.\pm 0.18 \times 10^{6}\right)$. Similar effect $(22 \%)$ was observed in a replicate (ID: $1.42 \times 10^{7}$ pixels \pm $0.16 \times 10^{7}$ vs $1.16 \times 10^{7}$ pixels $\left.\pm 0 \cdot 18 \times 10^{7}\right)$. A similarly significant increase $(24 \%, \quad P<0.05)$ was also observed when root fresh weight was analysed (1.57 \pm $0.59 \mathrm{~g}$ vs $1.27 \pm 0.63 \mathrm{~g})$. In this case, a batch of 60 -dayold plants was used. An example of the difference in the plant root systems is shown in the Fig. 1b.

\section{Bacillus subtilis colonization}

The ability of B. subtilis ALB629 to colonize the seedlings and its influence on naturally occurring micro-organisms were analysed in roots (primary and lateral), stem (epicotyl and hypocotyl), cotyledons, leaves (blade, petiole 
(a)

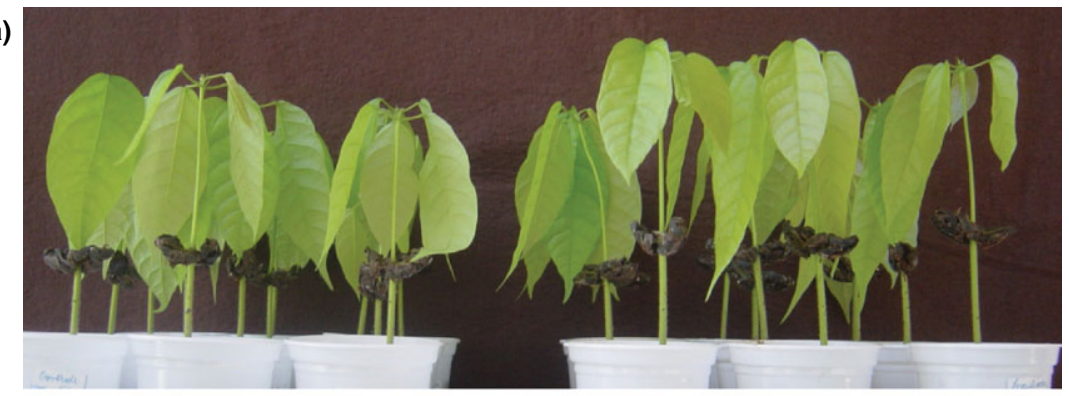

(b)

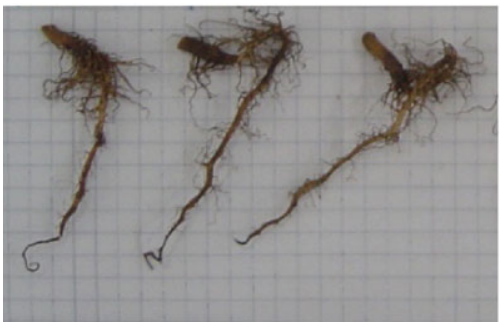

Control

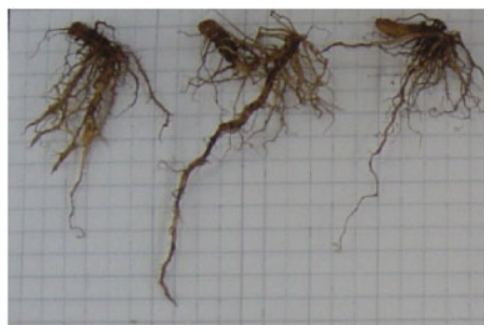

Inoculated

Figure 1 Effect of Bacillus subtilis ALB629 on the growth of Theobroma cacao seedlings. (a) Effect on plant height. (b) Effect on root system. Germinating cacao seeds were inoculated with ALB629 and cultivated for 30 days. Control: non-inoculated seedlings.

and veins) and shoot apex by observing the Bacillus recovery on LB agar. It was recovered from all examined tissues of the inoculated plants (Fig. 2a). To check its influence on micro-organisms that naturally occur in cacao, the plates were incubated for up to 12 days. Several different micro-organisms were observed in the control plates (Fig. 2b), which were not observed in the plates of ALB629-inoculated plants. Fungi and bacteria with Bacillus-like colony morphology were found among the culturable micro-organisms. However, these bacteria, isolated from plant cotyledons and leaves, presented genomic fingerprints different from B. subtilis ALB629 when analysed by BOX-PCR (Fig. 2c).

\section{Antagonism to phytopathogenic fungi}

To investigate the antagonistic effect of B. subtilis ALB629 on some phytopathogenic fungi, the mycelial growth and the presence of inhibition zones (halos) were evaluated by pairing ALB629 with the pathogens on PDA plates. For most of the tested pathogens, mycelial growth inhibition and halo formation were observed (Fig. 3). The strongest inhibition was observed for Colletotrichum. The fungi Colletotrichum sp. and C. gossypii presented clear inhibition zones. For F. solani, no halo was observed, but a different pattern of mycelial growth was visible in the presence of the Bacillus, as indicated by the arrow on the
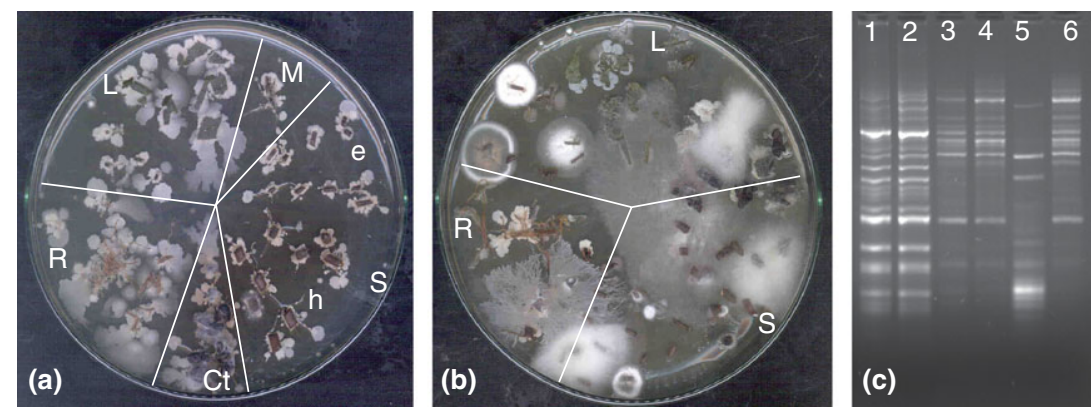

Figure 2 Recovery of Bacillus subtilis ALB629 from inoculated Theobroma cacao seedlings. Fragments from different tissues were placed on LB agar and incubated for 12 days, at $28^{\circ} \mathrm{C}$. (a) Inoculated plant. (b) Non-inoculated plant (control). L - leaf (blade, petiole and veins); $\mathrm{R}-$ roots (main and lateral); $\mathrm{S}$ - stem (e - epicotyl and $\mathrm{h}$ - hypocotyl); $\mathrm{Ct}$ - cotyledon; $\mathrm{M}$ - shoot apex with apical meristem. All micro-organisms grown in ' $a$ ' have a Bacillus-like morphology, while in 'b', a great diversity of micro-organisms is visible. (c) BOX-PCR genomic fingerprints of Bacillus-like bacteria from inoculated and non-inoculated plants. Lanes: 1) ALB629 from LB stock; 2) ALB629 from cotyledon of inoculated seedlings; 3-6) Indigenous Bacillus-like bacteria from cotyledons (lane 3-5) or leaves (lane 6) of non-inoculated seedlings. 
Colletotrichum sp.

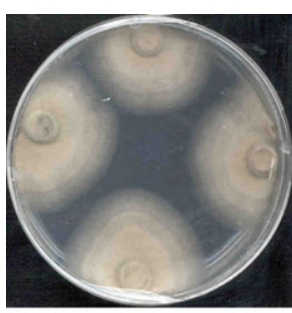

(b)

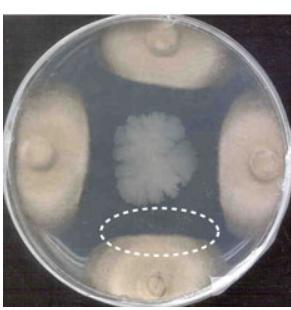

C. gossypii
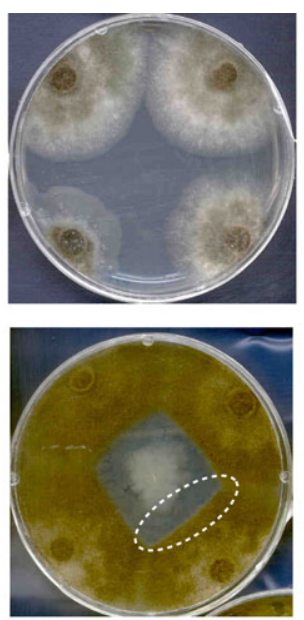

F. solani
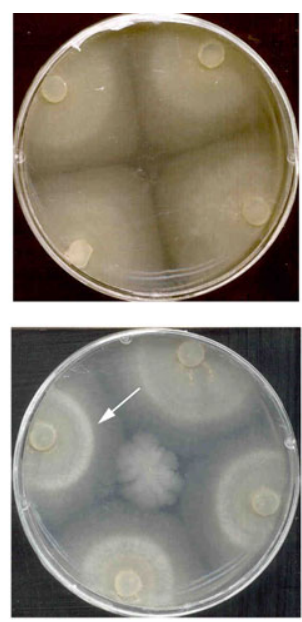

M. perniciosa
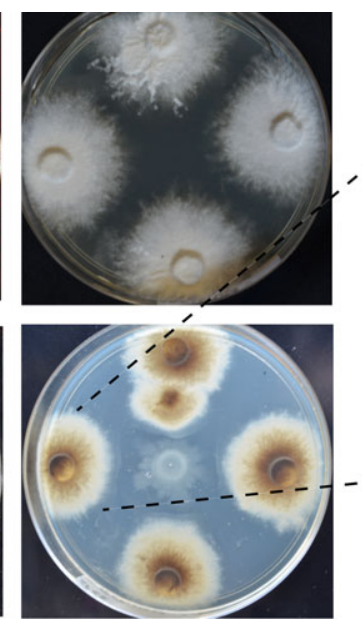

(c)

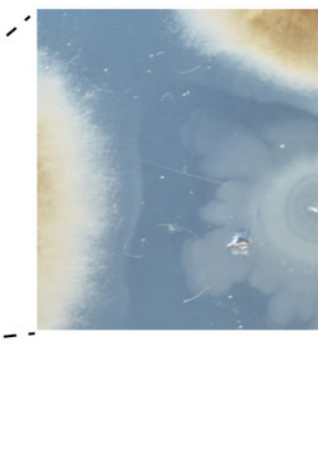

Figure 3 Antagonistic effect of Bacillus subtilis ALB629 on phytopathogenic fungi. ALB629 was inoculated in the centre of a PDA plate containing four equidistant fungal mycelial discs. The plates were incubated at $28^{\circ} \mathrm{C}$, photoperiod of $12 \mathrm{~h} / 12 \mathrm{~h}$, for 5 days. (a) Control - phytopathogens non-paired with ALB629. (b) Phytopathogens paired with ALB629. (c) Amplified image of the inhibition zone observed in the Moniliophthora perniciosa assay. Dotted white circles highlight the inhibition zone. Arrow indicates the ring-like pattern in the Fusarium solani mycelium, not seen in the control.

Fig. 3. In regard to the cacao pathogen M. perniciosa, it is noticeable that the fungal growth was affected by the bacteria, although a less prominent inhibition zone is formed.

In addition, mycelial growth of C. gossypii and M. perniciosa was inhibited when the supernatant of the ALB629 culture was added to the fungi cultivation medium (PDA). For C. gossypii, the mycelia diameter was approx. 3 times smaller than the control $(6 \cdot 46 \pm 0.25 \mathrm{~cm}$ vs $2.0 \mathrm{~cm})$. In the case of M. Perniciosa, it was about twice smaller $(3.36 \pm 0.15 \mathrm{~cm}$ vs $1.87 \pm 0.06 \mathrm{~cm})$.

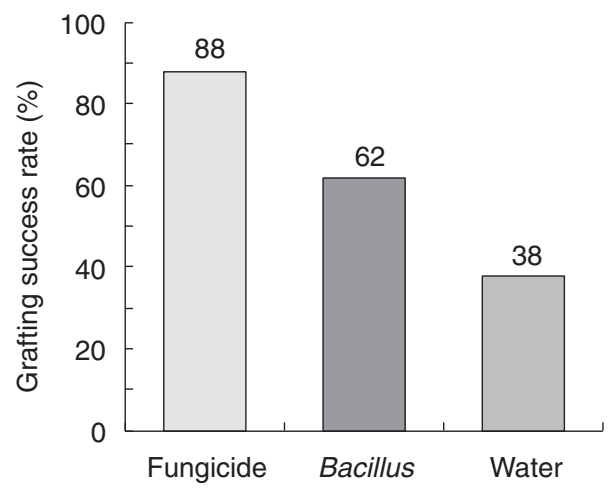

Figure 4 Effect of Bacillus subtilis ALB629 in the cacao-grafting success rate. Grafted plants were sprayed with ALB629 and the grafting success evaluated after 60 days. Water and fungicide-sprayed plants were used as negative and positive controls, respectively. Treatments were compared by generalized linear model, assigning binomial distribution. The differences were significant at $P<0.05$.

\section{Effect of Bacillus subtilis ALB629 on Theobroma cacao grafting}

To evaluate the effects of B. subtilis ALB629 on the cacao-grafting success rate, the isolate was used in the grafting procedure and compared to the use of fungicide (benomyl) or water. The data of the treatments were analysed by generalized linear model $(\mathrm{glm})$, assigning a binomial distribution. Statistically $(P<0 \cdot 05)$, the grafting success rate of plants treated with ALB629 was 24\% higher than the rate of plants treated with water and $26 \%$ lower than that of fungicide treated plants, as shown in the Fig. 4.

\section{Discussion}

Bacillus spp. are common endophytes of cacao trees and possibly play an important role in the trees' native microbial community (Melnick et al. 2011). In this work, we have studied the bacterial endophyte, B. subtilis ALB629, isolated from T. cacao, which presents several characteristics of interest for cacao cultivation. Recently, Leite et al. (2013) reported that this isolate acts as cacao plant growth promoter, assessed by number of leaves and plant height in 3-month-old seedlings. Here, we show that this isolate also influences positively the growth of the root system, as well as the aerial part of $T$. cacao seedlings, quite early in the development (30-day-old seedlings). At this stage, an increase in the foliar area, as well as in stem height, can be noticed in the inoculated plants. This 
increase in leaf area is consistent with the higher photosynthetic rate reported by Leite et al. (2013). These effects on growth can also be explained by the increase we observed in the root system, which leads to improved absorption of nutrients and water from the soil, resulting in a more vigorous plant.

The influence of endophytic bacteria on plant growth, including an increase in the root system, has been reported for several plant-endophyte systems. For instance, Taghavi and co-workers reported that the bacteria Stenotrophomonas proteamaculans 568, Pseudomonas putida W619 and Enterobacter sp. strain 638 accelerated roots and shoot formation in poplar trees. In addition, the later bacterium caused an increase in their biomass production (Taghavi et al. 2009). Bacillus sp. EUC10, isolated from eucalyptus, increased the growth of roots and aerial parts of plantlets from the hybrid Eucalyptus urograndis (Paz et al. 2012). In this regard, effects of Bacillus spp. on plant growth promotion have been reported for other systems. For example, it has been demonstrated that B. subtilis and Pseudomonas aeruginosa enhanced the plant growth, assessed by shoot height and dry biomass of tomato, okra and African spinach (Adesemoye et al. 2008). More recently, it was also demonstrated that the inoculation of strawberry plants with Pseudomonas and Bacillus stimulated plant growth and increased the number of fruits per plant (Esitken et al. 2010). The mechanisms by which promotion of plant growth occurs are diverse, including improvement of the plant nutritional level, synthesis of phytohormones and signalling molecules, and production of siderophores and volatile compounds (Ryu et al. 2004; Ryan et al. 2008; Maksimov et al. 2011). It is also known that Bacillus spp. can elicit induced systemic resistance (ISR) which, in most cases, results also in promotion of plant growth (Kloepper et al. 2004).

Another interesting characteristic of ALB629 is that it is an efficient colonizer of cacao leaves, stems and roots (Leite et al. 2013). Aiming to evaluate its spatial distribution in each organ, we analysed the presence of the endophyte in parts of the root (primary and lateral), stem (epicotyls and hypocotyl), cotyledons, leaves (blade, veins and petiole) and shoot apex. Actually, it was possible to isolate the inoculated Bacillus from every part analysed. Considering the antagonistic effect shown by the isolate (Fig. 3), the presence of this endophyte in the plant may be helpful to protect the cacao tree against pathogens such as Phytophthora spp. and M. perniciosa. The isolate presence in the shoot apex, including the apical meristem, is of particular interest in the case of M. perniciosa, as this pathogen invades the plant through meristematic tissues (Bowers et al. 2001). Furthermore, the Bacillus isolate systemic distribution might help impair the establishment of other pathogens.
We suggest that ALB629 have prevailed over indigenous micro-organisms such as fungi and other Bacillus-like bacteria, as shown by in vitro recovery and BOX-PCR experiments (Fig. 2). This prevalence can be a result of the inoculum strength, which may have favoured its competitiveness, but it can also be due to the antagonistic effect, especially considering the fungi growth inhibition observed (Figs. 2b and 3). In fact, B. subtilis ALB629 presented in vitro antagonism as demonstrated by the growth inhibition of some phytopathogenic fungi, such as M. perniciosa, Colletotrichum sp. and C. gossypii (Fig. 3). Moreover, in the field test, ALB629 was able to protect grafted plants, improving the graft union (Fig. 4), which is consistent with the antagonistic and/or growth promotion effects. These results suggest that $B$. subtilis ALB629 can be beneficial in terms of plant tolerance to pathogens. Experiments with $B$. subtilis against other phytopathogenic fungi elsewhere have shown similar responses. For example, preliminary studies with B. subtilis ALB629 indicate that it confers protection to cotton against the damping-off, a disease caused by C. gossypii var. cephalosporioides, when it is used in association with other bacteria (Medeiros et al. 2008). More recently, it was shown that B. subtilis, isolated from the rhizosphere of chilli, presented high antagonistic activity against C. gloeosporioides (Ashwini and Srividya 2013). In another study, the endophyte B. subtilis L25 presented antagonistic effects on the growth of the chestnut blight fungus Cryphonectria parasitica, a severe disease of chestnut (Castanea sativa), and suppressed the growth of a broad range of different fungal species (Wilhelm et al. 1998). Chaurasia and co-workers found that a strain of B. subtilis, originally isolated from the rhizosphere of tea bushes, restricted the growth and induced morphological abnormalities on four phytopathogenic fungi: F. oxysporum, Pythium afertile, Alternaria alternata and Cladosporium oxysporum. The effects were shown to be caused by the production of diffusible and volatile antifungal compounds (Chaurasia et al. 2005). Furthermore, Bacillus spp. are also able to produce chitinases that degrade chitin, a major constituent of the fungal cell wall (Kumar et al. 2012; Castillo et al. 2013). In the case of the ALB629 isolate, we have shown that it presents in vitro antifungal activity against different phytopathogens, both by direct contact (dual-culture assay) and by exposure of their mycelia to its supernatant compounds. This indicates that one or more antifungal compounds are produced by ALB629, but further analysis should be conducted to characterize them. Whether these compounds are synthesized and have antimicrobial activity in vivo must be also investigated, which is particularly challenging. In situ antibiotics production by bacteria, including B. subtilis, has been demonstrated by using analytical techniques, such as thin-layer chromatography, high-performance liquid chromatography (HPLC) 
and liquid chromatography-mass spectrometry (LC-MS). However, the inhibitory effects of these antibiotics on the micro-organisms growth in vivo remains unclear (Raaijmakers and Mazzola 2012).

The investigation conducted so far shows that B. subtilis ALB629 has potential to be employed in biotechnological applications for management of cacao, not only as a growth promoter for seedlings production (Leite et al. 2013), but also as a biological control agent. Furthermore, it appears as an interesting opportunity for further investigation on plant-endophyte-pathogen interactions, as well as a potentially valuable source for novel antifungal compounds.

\section{Acknowledgements}

The authors thank the Brazilian Agricultural Research Corporation - Embrapa - for financial support.

\section{Conflict of interest}

The authors declare no conflict of interest.

\section{References}

Acebo-Guerrero, Y., Hernández-Rodríguez, A., HeydrichPérez, M., Jaziri, M.E. and Hernández-Lauzardo, A.N. (2012) Management of black pod rot in cacao (Theobroma cacao L.): a review. Fruits 67, 41-48.

Adesemoye, A.O., Obini, M. and Ugoji, E.O. (2008) Comparison of plant growth-promotion with Pseudomonas aeruginosa and Bacillus subtilis in three vegetables. Braz J Microbiol 39, 423-426.

Ashwini, N. and Srividya, S. (2013) Potentiality of Bacillus subtilis as biocontrol agent for management of anthracnose disease of chilli caused by Colletotrichum gloeosporioides OGC1. 3 Biotech Available at: http://link. springer.com/article/10.1007/s13205-013-0134-4 [Accessed 01 August 2013].

Bae, H., Sicher, R.C., Kim, M.S., Kim, S.-H., Strem, M.D., Melnick, R.L. and Bailey, B.A. (2009) The beneficial endophyte Trichoderma hamatum isolate DIS 219b promotes growth and delays the onset of the drought response in Theobroma cacao. J Exp Bot 60, 3279-3295.

Bowers, J.H., Bailey, B.A., Hebbar, P.K., Sanogo, S. and Lumsden, R.D. (2001) The impact of plant diseases on world chocolate production. Plant Health Prog Available at: http://www.apsnet.org/publications/apsnetfeatures/ Pages/WorldChocolateProduction.aspx [Accessed 01 August 2013].

Castillo, H.F.D., Reyes, C.F., Morales, G.G., Herrera, R.R. and Aguilar, C. (2013) Biological control of root pathogens by plant-growth promoting Bacillus spp. In Weed and Pest
Control - Conventional and New Challenges eds. Soloneski, S. and Larramendy, M. InTech. ISBN 978-953-51-0984-6, DOI: 10.5772/54229 Available at: http://www.intechopen. com/books/weed-and-pest-control-conventional-and-newchallenges/biological-control-of-root-pathogens-by-plantgrowth-promoting-bacillus-spp-, [15 October 2013].

Chaurasia, B., Pandey, A., Palni, L.M.S., Trivedi, P., Kumar, B. and Colvin, N. (2005) Diffusible and volatile compounds produced by an antagonistic Bacillus subtilis strain cause structural deformations in pathogenic fungi in vitro. Microbiol Res 160, 75-81.

Chen, H., Wang, L., Su, C.X., Gong, G.H., Wang, P. and Yu, Z.L. (2008) Isolation and characterization of lipopeptide antibiotics produced by Bacillus subtilis. Lett Appl Microbiol 47, 180-186.

Esitken, A., Yildiz, H.E., Ercisli, S., Donmez, M.F., Turan, M. and Gunes, A. (2010) Effects of plant growth promoting bacteria (PGPB) on yield, growth and nutrient contents of organically grown strawberry. Sci Hortic 124, 62-66.

Hanada, R.E., Pomella, A.W.V., Soberanis, W., Loguercio, L.L. and Pereira, J.O. (2009) Biocontrol potential of Trichoderma martiale against the black-pod disease (Phytophthora palmivora) of cacao. Biol Control 50, 143-149.

ICCO (2010) International cocoa organization annual report 2009/2010. ICCO annual report, 1-67.

Kloepper, J.W., Ryu, C.-M. and Zhang, S. (2004) Induced systemic resistance and promotion of plant growth by Bacillus spp. Phytopathology 94, 1259-1266.

Koeuth, T., Versalovic, J. and Lupski, J.R. (1995) Differential subsequence conservation of interspersed repetitive Streptococcus pneumoniae BOX elements in diverse bacteria. Genome Res 5, 408-418.

Kogan, S.C., Doherty, M. and Gitschier, J. (1987) An improved method for prenatal diagnosis of genetic diseases by analysis of amplified DNA sequences. Application to hemophilia A. N Engl J Med 317, 985-990.

Kumar, D.P., Anupama, P.D., Singh, R.K., Thenmozhi, R., Nagasathya, A., Thajuddin, N. and Paneerselvam, A. (2012) Evaluation of extracellular lytic enzymes from indigenous Bacillus isolate. J Microbiol Biotechnol Res 2, 129-137.

Leite, H.A., Silva, A.B., Gomes, F.P., Gramacho, K.P., Faria, J.C., de Souza, J.T. and Loguercio, L.L. (2013) Bacillus subtilis and Enterobacter cloacae endophytes from healthy Theobroma cacao L. trees can systemically colonize seedlings and promote growth. Appl Microbiol Biotechnol 97, 2639-2651.

Lyngwi, N.A. and Joshi, S. (2014) Economically important Bacillus and related genera: a mini review. In Biology of Useful Plants and Microbes ed. Sen, A. pp. 33-43. New Delhi: Narosa Publishing House.

Maksimov, I.V., Abizgil'dina, R.R. and Pusenkova, L.I. (2011) Plant growth promoting rhizobacteria as alternative to 
chemical crop protectors from pathogens (review). Appl Biochem Microbiol 47, 333-345.

Medeiros, F.H., Souza, R.M., Ferro, H.M., Medeiros, F.C., Pomella, A.W., Machado, J.C., Neto, H.S., Soares, D.A. et al. (2008) Abstracts Submitted for Presentation at the 2008 APS Centennial Meeting. Phytopathology 98, S102.

Melnick, R.L., Zidack, N.K., Bailey, B.A., Maximova, S.N., Guiltinan, M. and Backman, P.A. (2008) Bacterial endophytes: Bacillus spp. from annual crops as potential biological control agents of black pod rot of cacao. Biol Control 46, 46-56.

Melnick, R.L., Suarez, C., Bailey, B.A. and Backman, P.A. (2011) Isolation of endophytic endospore-forming bacteria from Theobroma cacao as potential biological control agents of cacao diseases. Biol Control 57, 236-245.

Melnick, R.L., Bailey, B.A. and Backman, P.A. (2013) Bacterial endophytes of perennial crops for management of plant disease. In Bacteria in Agrobiology: Disease Management ed. Maheshwari, D.K. pp. 49-76. New York: Springer Berlin Heidelberg.

Ongena, M. and Jacques, P. (2008) Bacillus lipopeptides: versatile weapons for plant disease biocontrol. Trends Microbiol 16, 115-125.

Paz, I.C., Santin, R.C., Guimaraes, A.M., Rosa, O.P., Dias, A.C., Quecine, M.C., Azevedo, J.L. and Matsumura, A.T. (2012) Eucalyptus growth promotion by endophytic Bacillus spp. Genet Mol Res 11, 3711-3720.

Raaijmakers, J.M. and Mazzola, M. (2012) Diversity and natural functions of antibiotics produced by beneficial and plant pathogenic bacteria. Annu Rev Phytopathol 50, 403-424.

Rademaker, J.L.W. and de Bruijn, F.J. (1997) Characterization and classification of microbes by rep-PCR genomic fingerprinting and computer assisted pattern analysis. In DNA Markers: Protocols, Applications and Overviews eds. Caetano-Anollés, G. and Gresshoff, P.M. pp. 151-171. New York: John Wiley.

R-Core-Team (2013) R: A Language and Environment for Statistical Computing. Vienna, Austria: R Foundation for Statistical Computing. ISBN 3-900051-07-0, Available at: http://www.R-project.org/, [Accessed 08 August 2013].
Rubini, M.R., Silva-Ribeiro, R.T., Pomella, A.W., Maki, C.S., Araujo, W.L., Dos Santos, D.R. and Azevedo, J.L. (2005) Diversity of endophytic fungal community of cacao (Theobroma cacao L.) and biological control of Crinipellis perniciosa, causal agent of Witches' Broom Disease. Int $J$ Biol Sci 1, 24-33.

Ryan, R.P., Germaine, K., Franks, A., Ryan, D.J. and Dowling, D.N. (2008) Bacterial endophytes: recent developments and applications. FEMS Microbiol Lett 278, 1-9.

Ryu, C.M., Farag, M.A., Hu, C.H., Reddy, M.S., Kloepper, J.W. and Pare, P.W. (2004) Bacterial volatiles induce systemic resistance in Arabidopsis. Plant Physiol 134, 1017-1026.

Samuels, G.J., Suarez, C., Solis, K., Holmes, K.A., Thomas, S.E., Ismaiel, A. and Evans, H.C. (2006) Trichoderma theobromicola and T. paucisporum: two new species isolated from cacao in South America. Mycol Res 110, 381-392.

Taghavi, S., Garafola, C., Monchy, S., Newman, L., Hoffman, A., Weyens, N., Barac, T., Vangronsveld, J. et al. (2009) Genome survey and characterization of endophytic bacteria exhibiting a beneficial effect on growth and development of poplar trees. Appl Environ Microbiol 75, 748-757.

Versalovic, J., Schneider, M., de Bruijn, F.J. and Lupski, J.R. (1994) Genomic fingerprinting of bacteria using repetitive sequence-based polymerase chain reaction. Methods Mol Cell Biol 5, 25-40.

Wilhelm, E., Arthofer, W., Schafleitner, R. and Krebs, B. (1998) Bacillus subtilis an endophyte of chestnut (Castanea sativa) as antagonist against chestnut blight (Cryphonectria parasitica). Plant Cell, Tissue Organ Cult 52, 105-108.

Yamada, M.M., Faleiro, F.G., Lopes, U.V., Bahia, R.C., Pires, J.L., Gomes, L.M.C. and Melo, G.R.P. (2001) Genetic variability in cultivated cacao populations in Bahia, Brazil, detected by isozymes and RAPD markers. Crop Breed Appl Biotechnol 1, 377-384. 